\title{
Initiating Developments of Nursing Informatics Within a Caring Perspective for Philippine Nursing
}

https://doi.org/10.37719/jhcs.2020.v2i1.rna002

\author{
JOHN FRANCIS L. FAUSTORILLA JR, DNSc, MDM, MA, DipCS, RN, RM \\ https://orcid.org/0000-0002-0439-2174 \\ University of the Philippines Manila
}

Corresponding author's email: jlfaustorilla@up.edu.ph

\begin{abstract}
Nursing informatics, despite its rich evolution and dynamic nature remains an emerging field in the Philippines. With its inclusion as a critical content in the Bachelor of Science in Nursing Curriculum, Policies, and Standards in 2008, various interpretations and adaptations were made evident thereby influencing Philippine Nursing. Critical discussions, whether or not Nursing Informatics affect the focus of nursing with the integration of information and communication technologies into nursing service delivery systems continue to exist. It is imperative that better understanding of the contributions of Nursing Informatics on Philippine Nursing from a historical perspective and declaring its implications for Philippine Nursing Practice initiated within a Caring viewpoint are addressed and illuminated. This paper aims to provide a description of the initiation of Nursing Informatics in the hope of establishing its ontological and epistemological position while providing a clearer understanding of its historical developments and influences on Philippine Nursing initiated within a caring perspective in a highly technological world.
\end{abstract}

Keywords: BSN Curriculum, eHealth, Nursing, Nursing Informatics, Philippine Nursing

\section{Introduction}

- he emergence of information and communication technologies as adjunct tools to address health care needs (ICT4Health) in the biomedical field is starting to become prominent in the Philippines. This phenomenon starts to emanate even in the nursing context not only in the academic perspective but also in the practice settings and research undertakings. A few studies have been documented in the Philippines talking about integrating eHealth in Nursing Education, Research and Practice despite its current inclusion by the Board of Nursing (n.d.) in the National Core 
Competency Standards for Filipino Nurses and with the Commission of Higher Education (CHED) including this concept as a subject in its memorandum 5 series of 2008 and memorandum 14 series of 2009. Indeed, this poses an urgent concern to visit its value and importance in the delivery of nursing care, and probably how it impacts in the concept of caring among nurses with the advancement of technology and machines in the 21 st century, in the context of a developing country such as the Philippines. Hence, this paper aims to define what nursing informatics is and provide an understanding of how caring can be applied in a technological world through a comprehensive review of the existing literatures pertaining to the topic matter.

\section{Evolution of Nursing Informatics: Definition and Frameworks}

As an emerging field of Nursing in the Philippines, there remains a great deal of challenge posed to better understand what nursing informatics is. This section aims to present the continuing evolution of its definition and the various frameworks holding the ground of nursing informatics.

\section{An Evolving Definition of Nursing Informatics}

Nursing Informatics became more prominent in the Philippines during its inclusion in the new Bachelor of Science in Nursing Policies and Standards, thus affecting the curriculum in 2008. Since then, the concept eHealth was seen in the Nursing profession from three perspectives: (1) how the Board of Nursing (n.d.) will have to revisit their National Core Competency Standards for Filipino Nurses from the current outlined competencies (Table 1) and (2) how the Board of Nursing or the appropriate Nursing Organization (e.g., a nursing informatics organization or the higher educational institutions (HEls) will have to align Nursing Informatics competencies among Beginning Nurses and Advance Nurse Practitioners with the creation of the National Nurse Career Progression framework based on the competencies defined by Staggers et al. (2001), Chang et al. (2011) and the American Nurses Association (ANA, 2014) and (3) how will this concept affect the context of Caring in the Nursing Profession in the Philippines. However, there remains the need to define clearly what nursing informatics is before one gets caught in the mix of these curricular challenges in the Philippine Nursing Education System.

Staggers and Thomson (2002) cited three main themes to cluster the definitions of nursing informatics: (1) information technology-oriented, (2) conceptually oriented, and (3) role-oriented definitions.

\section{Information Technology-Oriented definitions}

Nursing Informatics was first defined according to its high inclination towards information technology in nursing. Scholes and Barber (1980) defined it as "the application of computer technology to all fields of nursing - nursing service, nursing education, and nursing research." Ball and Hannah (1984), on the other hand, drew their definition as a jump-off from medical informatics, 
asserting the inclusion of all health care professionals in this concept. However, Hannah (1985) focused on technology and incorporated nursing role within the definition. Zielstorff et al. (1990) likewise supported the importance of technology in nursing informatics. Saba and McCormick (1996) further stressed technology in line with their definition:

The use of technology and/or a computer system to collect, store, process, display, retrieve, and communicate timely data and information in and across health care facilities that administer nursing services and resources, manage the delivery of patient and nursing care, link research resources and findings to nursing practice, and apply educational resources to nursing education.

\section{Conceptually Oriented definitions.}

Several authors also showed their shift from technology-focused definitions towards conceptually-oriented definitions. Schwirian (1986) emphasized the importance of a proactive and model-driven definition and stressed that nursing informatics knowledge should have a grounding and "focus, direction, and cumulative properties." More popularly, Graves and Corcoran (1989) gave a widely cited definition of nursing informatics in a more conceptually oriented fashion as a combination of computer science, information science, and nursing science combined to assist in the management and processing of nursing data, information and knowledge to support the practice of nursing and the delivery of nursing care. Likewise, Turley (1996) enhanced this conceptually oriented definition by incorporating cognitive science - memory, problem solving, mental models, skill acquisition, language processing, and visual attention - to the original three sciences in Graves and Corcoran's definition.

\section{Role-oriented definitions.}

With the emergence of informatics nurse specialists in the late 1980s, nursing informatics gained significant momentum especially with its recognition by the ANA as a specialty field of nursing. ANA (1992) defined nursing informatics as:

A specialty that integrates nursing science, computer science, and information science in identifying, collecting, processing, and managing data and information to support nursing practice, administration, education, and research and to expand nursing knowledge. The purpose of nursing informatics is to analyze information requirements; design, implement and evaluate information systems and data structures that support nursing; and identify and apply computer technologies for nursing.

In 1994, the ANA improved the definition to respond for the need to create a certification examination in this field of specialization:

Nursing informatics is the specialty that integrates nursing science, computer science, and information science in identifying, collecting, processing, and managing data and information to support nursing practice, administration, education, research, and expansion of nursing knowledge. It supports the practice of all nursing specialties, in all sites and settings, whether at the basic or advanced level. The practice includes the development of applications, tools, processes, and structures that assist nurses with the management of data in taking care of patients or in supporting their practice of nursing. 
The advancement of nursing informatics further advanced the definitions initially set by ANA (2001), which is used up until now and includes in great detail information structures, processes and technology as implied in this definition:

Nursing Informatics is a specialty that integrates nursing science, computer science, and information science to manage and communicate data, information, and knowledge in nursing practice. Nursing informatics facilitates the integration of data, information, and knowledge to support patients, nurses, and other providers in their decision-making in all roles and settings. This support is accomplished through the use of information structures, information processes, and information technology.

\section{Frameworks Defining Nursing Informatics}

There had been numerous frameworks that attempted in evaluating nursing informatics and its competencies. However, they range from frameworks differing in focus such as generic evaluation frameworks, human behavior, social/organizational relationships, and software life cycle. Their main characteristics can be summarized as follows (Currie, 2005):

Table 1. Characteristic of Frameworks used to evaluate nursing informatics

\begin{tabular}{|c|c|c|c|c|c|}
\hline Author(s) & Framework & $\begin{array}{l}\text { Context- } \\
\text { centric }\end{array}$ & $\begin{array}{l}\text { User- } \\
\text { centric }\end{array}$ & $\begin{array}{l}\text { Functionality } \\
\text {-centric }\end{array}$ & $\begin{array}{l}\text { Theory } \\
\text { Based? }\end{array}$ \\
\hline \multicolumn{6}{|c|}{ Generic evaluation frameworks } \\
\hline Stead et al. & $\begin{array}{l}\text { Development Evaluation } \\
\text { Matrix }\end{array}$ & Yes & Yes & Yes & No \\
\hline Friedman and Wyatt & $\begin{array}{l}\text { House's eight approaches } \\
\text { to research }\end{array}$ & No & Yes & Yes & No \\
\hline Shaw & CHEATS & Yes & Yes & Yes & No \\
\hline \multicolumn{6}{|c|}{ Frameworks that focus on human behavior } \\
\hline Patel et al. & Cognitive psychology & Yes & Yes & Yes & Yes \\
\hline Dixon & Behavioral psychology & Yes & Yes & Yes & Yes \\
\hline \multicolumn{6}{|c|}{ Frameworks that focus on social/organizational relationships } \\
\hline Kaplan & Social interactionism & Yes & Yes & No & No \\
\hline Berg & Sociotechnical Approach & Yes & Yes & Yes & Yes \\
\hline Effken & $\begin{array}{l}\text { Carper's four ways of } \\
\text { knowing }\end{array}$ & Yes & Yes & Yes & Yes \\
\hline Anderson & Social network analysis & Yes & Yes & Yes & Yes \\
\hline Westbrook et al. & $\begin{array}{l}\text { Multi-disciplinary, multi- } \\
\text { method framework }\end{array}$ & Yes & Yes & No & No \\
\hline \multicolumn{6}{|c|}{ Frameworks that focus on software life-cycle } \\
\hline Grant et al. & TEAM methodology & Yes & Yes & Yes & Yes \\
\hline Kushniruk & $\begin{array}{l}\text { System development life } \\
\text { cycle }\end{array}$ & Yes & Yes & Yes & Yes \\
\hline
\end{tabular}


Among the frameworks that focus on generic evaluation frameworks, Stead (1994), Friedman and Wyatt (1997), and Shaw (2002) mainly emerged among these. Basically, Stead's development evaluation matrix focused on expert reviews and 'qualitative studies' while Friedman and Wyatt's house's eight approaches to research utilizes observation, interviews, document and artifact analysis in its evaluation. On the other hand, Shaw's CHEATS recommended the use of thematic analysis of subjects' experiences and perceptions.

When dealing with human behavior, Patel et al. (1999) came up with a framework on cognitive psychology, which advocated evaluation using propositional analysis and semantic analysis. Dixon's behavioral psychology (1999), however, speculated interviews with no analysis process specified in evaluating framework for informatics.

As to social/organizational relationships, Kaplan's social interactionism (2001) prescribed evaluating informatics using ethnographic interviews and observations. Berg's socio-technical approach (1999) uses participant observation, interviews, user participation in development. Effken (2002) adopted Carper's four ways of knowing and postulated evaluating using cognitive work analysis. Anderson's social network analysis (2002) makes use of email and communication to evaluate informatics. Westbrook et al. (2004) came up with the multi-disciplinary, multi-method framework, with an attempt to evaluate informatics through interviews, focus groups, and ethnography.

Software life-cycle authors also utilized their own mechanism of evaluating informatics. Grant et al. (2002) came up with the TEAM methodology with questionnaire and video-taping their means of evaluating informatics. Kushniruk's systems development life cycle (2002), however, makes use of cognitive task analysis, focus groups, and usability testing to assess informatics in nursing.

To this end, these frameworks were considered in developing evaluative measures in nursing informatics. Currently, with the emergence of evidence-based practice, competency-based nursing appraisal systems have been developed and are currently set in place to be utilized by institutions as reflected by Chang et al. (2011) and the ANA.

\section{Caring and Technology: Advantages and Challenges in Nursing}

Several studies were able to describe how caring applies in a technological environment. These include, but not limited to, Ray's Theory of Bureaucratic Caring (Turkel, 2007), Locsin's (2005) Technological Competency as Caring in Nursing, McDonald's (Agency for Healthcare Research and Quality [AHRQ], 2011) Care Coordination, Locsin and Purnell's (2007) Rapture and Suffering with Technology in Nursing, Kongsuwan and Locsin's (2010) Thai nurses' experience of caring for persons with life-sustaining technologies in intensive care settings. 


\section{Integrating the Use of Technology in Caring}

Central to the idea of these literature is the use of information and communication technologies to support the delivery of nursing care. As Turkel (2007) highlighted, Dr. Ray included technology as part of the concepts in her Theory of Bureaucratic Caring. She emphasizes that technological factors consist of non-human resources and the knowledge of using them to perform nursing tasks and client services. Similarly, Locsin (2005) integrates the importance of technology and its competencies as caring in nursing specifically in the quest to complete human beings, aid in case as machine technologies and mimicking human beings and activities. In addition, McDonald (AHRQ, 2011) integrates health information technology - enabled coordination as part of the mechanisms for achieving care coordination as a broad approach.

Likewise, Barnard and Margarete (2000) argues that a humanist view on technology as nonhuman and non-natural is not enough to claim a dehumanizing client experience. They assert that the use of these technologies by the nurses determines the impersonal care that clients receive. These include user-specific contexts including attribution of an individualistic, socio-cultural, political and economic view of what is human in a technological system.

In addition, Strople and Ottani (2006) reports that electronic systems is seen as a useful tool in the shift report process towards better patient care provided full utilization of its capacity. These technologies have the potential to improve patient data management. As such, computer-generated shift reports, when fully understood, are seen to improve the quality, effectiveness, and efficiency of patient-centered shift reports and contribute significant improvement in patient care safety and outcomes. A similar finding in realizing the potential of informatics tools usage is depicted in the study by Swan et al. (2004). They assert that tools such as predictive modeling, artificial intelligence and evidence-based practice algorithms allow the forecast of client health care needs. These methods thus enhance the nursing care management of patient problems.

Quality assessment and improvement are also areas identified by Henry (1995) where nursing informatics play a significant role. She asserts that with the increase in care provision information, technology can greatly improve information management and processing. However, she posits that there still remain challenges in the attainment of knowledge and skills necessary to process these nursing care-related information.

Aside from offline nursing informatics tools, web-based platforms have also emerged to enhance the experience of nursing care provision. Bond (2006) sees that the internet provides a relatively powerful mechanism to ensure the delivery of nursing interventions such as education and chronic disease support. Goldstein et al. (2007) also asserts that wireless technology coupled with tablet devices allow greater portability for nurses in caring for clients with acute pain. 


\section{Challenges in the Adoption of Caring in a Technological World}

Despite the positive impacts of technology use in nursing care, there are also challenges that are perceived in the workplace. Several studies also assert that it is still unclear whether electronic nursing documentation indeed improves patient care outcomes. (Kelley et al., 2011; Gunningberg et al., 2009; Saranto \& Kinnunen, 2009; Qiuping et al., 2009; Eland-de Kok et al., 2011). Moreover, Locsin and Purnell (2007) poses a challenging question whether nurses will remain caring despite the emergence of technology, cybergenetic organisms and other "technosapiens." Kongsuwan and Locsin (2010) likewise see differing insecurities in the use of technology. They view this instance as a possible avenue for nurses to allow technology to hinder them from viewing people as wholes. Given these dynamics between caring as a concept revolving around the technological environment, the next section presents a more focused lens on the frameworks and literatures trying to define the nature of nursing informatics.

Resistance of the nurse on the technology use is also a valid concern raised by Timmons (2003) when he reviewed nurses' experience in three UK NHS hospitals. While the implementation of the technology was not halted, the resistance among these nurses persisted through minimizing use and extensive criticism of the systems. They were also concerned about system security, skills deterioration, and detraction from individualized care, among others.

Usability and flexibility are another concern posed by Ward et al. (2008) when they review literatures on the attitudes of health care staff to information technology. They see that systems were created for the workplace, but they were not "fit for purpose." There are also seen issues on the ability of the users to integrate these technologies into their work patterns. Given this, successive education and training were needed to support the staff in the use of these IT systems. A similar experience among nurses and midwives were also expressed in the study made by Darbyshire (2004) when he did a study on 53 practitioners across five Australian states. There was disappointment in the user experience of these technologies and was associated with non-enhancement of their clinical practice and patient care. The technological solutions seem to have no significant impact in their patient care outcomes, causing them to look for where the "real nursing" is alongside the incompatibilities and non-responsiveness of these systems to patient care.

\section{Theoretical Framework}

Having evaluated various nursing informatics definitions and frameworks, it is imperative that the caring component be integrated in this quest to advance nursing informatics in the Philippines. Locsin (2005) in his theory, Technological Competency as Caring in Nursing focused the process of nursing as grounded in Knowing persons as a framework for Nursing Practice. This theory presents a clear perspective of caring for persons who live and grow in caring (Boykin \& Schoenhofer, 2001). 
The competencies described in Locsin's theory is addressed within other conceptual and theoretical frameworks which inform contemporary nursing informatics. These include the Fundamental Patterns of Knowing in Nursing by Carper (1978, as cited by Pipe et al., 2005) which were intended to present a varied modality of validating nursing knowledge on informatics among beginning nurses in education, practice and research. This may be presented through, but not limited to, empirical, personal, ethical and aesthetic knowing.

Furthermore, the combined formulated competencies on informatics of nurses at the beginner level by Chang et al. (2011) and the ANA (2014) version addressed how the ways of knowing by Carper may develop categories that will serve as a counterpart of the task-based informatics competencies that can elicit caring-infused informatics competencies. Moreover, when one looks "through the lens of Nursing as Caring using technologies competently to appreciate persons as whole in the moment" (Boykin \& Schoenhoffer, 2001, as cited by Locsin, 2005), nurses at the beginner level who might be competent with task-based skills may now be assessed based on the parameters that measure how technological advancements enhance their caring imperatives for their nursing care.

This attempt at looking at the caring component is guided by the "calls for nursing which affirm, support, and celebrate who a person is and what a person" is amidst the use of information technology in nursing service delivery. Further enhancement in caring among persons can be seen when responses to calls for nursing is monitored to "sustain and enhance who is person and what is person?" In this end, not only does a nurse informaticist able to address his technical skills in addressing nursing care for clients, but he is also able to keep in mind the practice of nursing grounded on caring through knowing persons.

\section{Conclusion}

Amidst the technological advancements in health care, caring remains as a central concept among the nursing professionals in the delivery of health care services. Having seen the dynamics between caring and technology through the various literatures and frameworks, there are now challenges set as to how we will define the competencies required of nurses and nursing informaticians at various levels. Truly, there still remain opportunities for the development of a more robust and responsive nursing informatics scope and standards of practice that highlights how nurses can truly function in the essence of caring. 


\section{References}

Agency for Healthcare Research and Quality. (2011). Care coordination measurement framework: Care coordination measures atlas. http://www.ahrq.gov/professionals/systems/long-term-care/resources/ coordination/atlas/chapter3.html\#fig2

American Nurses Association Council on Computer Applications in Nursing. (1992). Report on the designation of nursing informatics as a nursing specialty. Congress of Nursing Practice Unpublished Report. Available from: American Nurses Association, Washington, DC.

American Nurses Association. (1994). The scope of practice for nursing informatics. ANA publication NP907.5M 5/94.

American Nurses Association. (2001). Scope and standards of nursing informatics practice. Washington, D. C.: American Nurses Publishing

American Nurses Association. (2014). Nursing Informatics: Scope and standards of practice. (2nd ed.). https://www.nursingworld.org/nurses-books/nursing-informatics-scope-and-standards-of-practice2nd-ed/

Anderson, J. G. (2002). Evaluation in health informatics: social network analysis, Computers in Biology and Medicine, 32(3) 179-193.

Ball, M.J., \& Hannah, K.J. (1984). Using computers in nursing. Reston Publishing.

Barnard, A., \& Margarete, S. (2000). Technology and humane nursing care: (ir)reconcilable or invented difference? http://gse.buffalo.edu/fas/bromley/classes/socprac/readings/Barnard.pdf.

Berg, M. (1999). Patient care information systems and health care work: a sociotechnical approach, International Journal of Medical Informatics, 55(2), 87-101.

Board of Nursing - Professional Regulation Commission. (n.d.). National Competency Standards for Filipino Nurses. http://bon2.cebuinternetsolutions.com/index.php/downloads-bon-sub-menu-41/13-nursingmanuals-and-documents/261-national-competency-standards-for-filipino-nurses.html

Bond, G. (2006). Lessons learned from the implementation of web-based nursing intervention. http://knowledgetranslation.ca/sysrev/articles/project21/Ref\%20ID\%201729-20090621205644.pdf.

Boykin, A., \& Schoenhofer, S. (2001). Nursing as Caring: A Model for Transforming Practice. United States of America: Jones and Bartlett Publications, Inc. and National League for Nursing.

Chang, J., Poynton, M. R., Gassert, C. A., \& Staggers, N. (2011). Nursing informatics competencies required of nurses in Taiwan. International Journal of Medical Informatics, 80(5), 332-340. https://doi.org/10.1016/j.ijmedinf.2011.01.011

Currie, L. (2005) Evaluation frameworks for nursing informatics. http://cocfs3.nccu.edu.tw/260509/\%E5\%B0\% A4\%E6\%9D\%BE\%E6\%96\%87\%E8\%80\%81\%E5\%B8\%AB/temp/05101918294803660.pdf

Darbyshire, P. (2004). 'Rage against the machine?': nurses' and midwives' experiences of using Computerized Patient Information Systems for clinical information. http://s3.amazonaws.com/publicationslist.org/ data/philip.darbyshire/ref-34/Rage\%20paper\%20JCN.pdf.

Dixon, D. R. (1999). The behavioral side of information technology, International Journal of Medical Informatics, 56(1-3), 117-123.

Effken, J. A. (2002). Different lenses, improved outcomes: a new approach to the analysis and design of healthcare information systems, International Journal of Medical Informatics, 65(1) 59-74.

Eland-de Kok, P., van Os-Medendorp, H., Vergouwe-Meijer, A., Bruijnzeel-Koomen, C., \& Ros, W. (2011). A systematic review of the effects of e-health on chronically ill patients. Journal of Clinical Nursing, 20(21/22), 2997-3010. https://doi.org/10.1111/j.1365-2702.2011.03743.x 
Friedman, C.P., \& Wyatt, J.C. (1997). Evaluation Methods in Medical Informatics. Springer-Verlag

Grant, A., Plante, I., \& Leblanc, F. (2002). The TEAM methodology for the evaluation of information systems in biomedicine, Computers in Biology and Medicine, 32(3), 195-207. https://doi.org/10.1016/s00104825(02)00015-x

Graves, J. R., \& Corcoran, S. (1989). The study of nursing informatics. Image: The Journal of Nursing Scholarship. https://doi.org/10.1111/j.1547-5069.1989.tb00148.x

Goldstein, D. H., Wilson, R., \& VanDenKerkhof, E. G. (2007). Electronic Monitoring in an Acute Pain Management Service. Pain Medicine, 8 (3) S94-S100. https://doi.org/10.1111/j.15264637.2007.00373.x

Gunningberg, L., Fogelberg-Dahm, M., \& Ehrenberg, A. (2009). Improved quality and comprehensiveness in nursing documentation of pressure ulcers after implementing an electronic health record in hospital care. Journal of Clinical Nursing, 18(11), 1557-1564. https://doi.org/10.1111/j.13652702.2008.02647.x

Hannah, K. J., Guillemin, E. J., Conklin, D. N., Hannah, K. J. (1985). Current trends in nursing in informatics: implications for curriculum planning. In: Hannah, K.J, Guillemin, E.J., Conklin, D.N. (eds). Nursing Uses of Computers and Information Science. Proceedings of the IFIP/IMIA International Symposium on Nursing Uses of Computers and Information Science (pp. 181-187). Elsevier

Henry, S. (1995). Informatics: Essential infrastructure for quality assessment and improvement in Nursing. http://171.67.114.118/content/2/3/169.full.pdf.

Kaplan, B. (2001). Evaluating informatics applications-some alternative approaches: theory, social interactionism, and call for methodological pluralism. International Journal of Medical Informatics, 64 (1) 39-56.

Kelley, T. F., Brandon, D. H., \& Docherty, S. L. (2011). Electronic Nursing Documentation as a Strategy to Improve Quality of Patient Care. Journal of Nursing Scholarship, 43(2), 154-162. https://doi.org/10.1111/j.1547-5069.2011.01397.x

Kongsuwan, W. \& Locsin, R.C. (2010). Thai nurses' experience of caring for persons with life-sustaining technologies in intensive care settings: A phenomenological study. http://www.intensivecriticalcare nursing.com/article/S0964-3397(10)00118-7/abstract.

Kushniruk, A. W. (2002). Evaluation in the design of health information systems: application of approaches emerging from usability engineering, Computers in Biology and Medicine, 32 (3) 141-149.

Lindberg, D. A., Kaihara, S., Scholes. M., \& Barber, B. (1980). Towards nursing informatics. In: DAD Lindberg \& S. Kaihara (eds) (pp. 7-73). MEDINFO. North-Holland,

Locsin, R. C. (2005). Technological Competency as Caring in Nursing. National Book Store, Inc. and Sigma Theta Tau International.

Locsin, R. C., \& Purnell, M. J. (2007). Rapture and suffering with technology in nursing. International Journal for Human Caring, 11(1), 38-43.

Patel, V. L., Kaufman, D. R., Allen, V. G., Shortliffe, E. H., Cimino, J. J., \& Greenes, R. A. (1999) Toward a framework for computer-mediated collaborative design in medical informatics. Methods of Information in Medicine, 38(3), 158-176.

Pipe, T. B, Wellik, K., Buchda, V, Hansen, C., \& Martyn, D. (2005). Implementing Evidence Based Nursing Practice: Evidence-Based Nursing Practice. Urologic Nursing, 25(5), 365-370

Quuping, P., Yuan-Xiang, M., Gibbons, G. H., \& Gregory, S. (2009). Effectiveness of an intervention to improve the documentation required for diagnosis of metabolic syndrome in clinics serving African-American patients. Quality In Primary Care, 17(3), 191-196. 
Saba, V. K., \& McCormick, K. A. (1996). Nursing Informatics: Essentials of Computers for Nurses (pp. 221263). McGraw-Hill

Saranto, K., \& Kinnunen, U. (2009). Evaluating nursing documentation - research designs and methods: systematic review. Journal of Advanced Nursing, 65(3), 464-476. https://doi.org/10.1111/j.13652648.2008.04914.x

Schwirian, P. (1986). The NI pyramid: a model for research in nursing informatics. Computers in Nursing, 4(3), 134-136.

Shaw, N. T. (2002). CHEATS: a generic information communication technology (ICT) evaluation framework. Computers in Biology and Medicine, 32 (3) 209-220.

Staggers, N., Gassert, C. A., \& Curran, C. (2001). Informatics competencies for nurses at four levels of practice. The Journal of Nursing Education, 40(7), 303-316.

Staggers, N. \& Thompson, C. (2002). The evolution of definitions for Nursing Informatics: A critical analysis and revised definition. http://jamia.bmj.com/content/9/3/255.long\#ref-4.

Stead, W., Haynes, R.B., Fuller, S., Friedman, C., Travis, L., Beck, J. R, Fenichel, C., Chandrasekaran, B., Buchanan, B., Abola, E., Sievert, M., Gardner, R., Messrle, J., Jaffe, C., Pearson, W., \& Abarbanel, R. (1994). Designing medical informatics research and library-resource projects to increase what is learned, Journal of American Medical Informatics Association, 1(1) 28-33.

Strople, B and Ottani, P. (2006). Can technology improve intershift report? What the research reveals. https://depts.washington.edu/respcare/public/hmc_files/journal_club/articles/20090406/Can_technol ogy_improve_intershift_report.pdf.

Swan, B.A., Lang, N., \& McGinley, A. (2004). Access to quality care: Links between evidence, nursing language, and informatics. http://jdc.jefferson.edu/cgi/viewcontent.cgi?article=1006\&context=nursfp\&seiredir= 1\&referer=http\%3A\%2F\%2Fscholar.google.com.ph\%2Fscholar\%3Fstart\%3D40\%26q\%3Dcaring\%2 Bin\%2Bthe \%2Btechnological\%2Bage \%3A\%2Bnursing\%2Binformatics\%2Bin\%2Baction\%26hl\%3Dt I\%26as_sdt\%3D0\%2C5\%26as_vis\%3D1\#search=\%22caring\%20technological\%20age\%3A\%20nur sing\%20informatics\%20action $\% 22$.

Timmons, S. (2003). Nurses resisting information technology. http://www.interruptions.net/literature/TimmonsNursinq03.pdf.

Turkel, M. C. (2007). Dr. Marilyn Ray's Theory of Bureaucratic Caring. http://marilynray.com/wpcontent/uploads/2012/10/Theory-of-Bureaucratic-Caring.pdf

Turley, J. (1996). Toward a model for nursing informatics. Image: The Journal of Nursing Scholarship, 28, 309313. https://doi.org/10.1111/j.1547-5069.1996.tb00379.x

Ward, R., Stevens, C., \& Brentall, P., \& Briddon, J. (2008). The attitudes of health care staff to information technology: a comprehensive review of the research literature. Health Information and Libraries Journal, 25, 81-97. https://doi.org/10.1111/j.1471-1842.2008.00777.x

Westbrook, J. I., Braithwaite, J., ledema, R., Coiera, E.W. (2004). Evaluating the Impact of Information Communication Technologies on Complex Organizational Systems: A Multi-Disciplinary, Multimethod Framework. Studies in Health Technology an Informatics,. 11, 1323-1327.

Zielstorff, R., Abraham, L., Werley, H., Saba, V.K., Schwirian, P. (1990). Guidelines for adopting innovations in computer-based information systems for nursing. Computers, Informatics, Nursing, 7(5), 203-208. 
John Francis L. Faustorilla Jr, DNSc, MDM, MA, DipCS, RN, RM, is currently a part-time a Lecturer at the University of the Philippines Manila (UP Manila) College of Medicine and Associate Professorial Lecturer IV at the Pamantasan ng Lungsod ng Maynila (PLM) College of Nursing. He is also a freelance ISO Auditor and Consultant at TUV Rheinland Philippines. He finished his BS in Nursing from PLM College of Nursing, MA in Nursing from St Paul University Manila, MDM from Asian Institute of Management, Doctor in Nursing Science from St Paul University Philippines and Diploma in Computer Science from the University of the Philippines Open University. His research interests include nursing informatics, entrepreneurship in nursing, quality management system, occupational health and safety management system, environmental management system, information security management system, business continuity management system, and educational organization management system applied to nursing and allied health care practice. 